\title{
A Crise Política do Final da Era Vargas: Uma Interpretação Sob a Ótica da Economia Política Neo-institucionalista ${ }^{+}$
}

\author{
- Newton Paulo Bueno *
}

\begin{abstract}
RESUMO
Problemas de ação coletiva em geral não são passíveis de serem solucionados por negociações entre as partes envolvidas, requerendo a mobilização política de grupos de interesses. A economia neo-institucionalista tem recentemente incluído em suas análises uma abordagem de economia política para estudar essas situações, definidas como dilemas sociais. O presente trabalho objetiva mostrar como isso vem sendo feito no campo teórico, ilustrando a teoria com uma análise dos eventos dramáticos que culminaram com o suicídio de Getúlio Vargas, processo este que se considera insuficientemente explicado pelas interpretações tradicionais.
\end{abstract}

\section{PALAVRAS-CHAVE}

Vargas, teoria da ação coletiva, nova economia institucional, dilemas de ação coletiva, Brasil

\begin{abstract}
Problems of collective action are not, in general, susceptible to be overcome by negotiations among the relevant agents, requesting instead political mobilization of interest groups. The new institucional economics has included recently an approach of political economy in its analysis to study those situations, defined as social dilemmas. The present work aims to show how these studies have been made, in the theoretical field, illustrating the theory with an analysis of the dramatic events that culminated with Getúlio Vargas's suicide, a process which we consider insufficiently explained by traditional interpretations.
\end{abstract}

\section{KEY WORDS}

Vargas, theory of collective action, new institutional economics, social dilemmas, Brazil

\author{
JEL CLASSIFICATION \\ N46
}

\footnotetext{
- O autor agradece ao CNPq pelo apoio financeiro à sua atividade de pesquisa, da qual este trabalho deriva.

* Professor Doutor do Departamento de Economia da Universidade Federal de Viçosa. E-mail: npbueno@ufv.br. Universidade Federal de Viçosa, Departamento de Economia, Campus, CEP: 36570-000.

(Recebido em agosto de 2005. Aceito para publicação em novembro de 2005).
} 


\section{INTRODUÇÃO}

Na última década do século passado a nova economia institucional (NEI) se consolidou como integrante do núcleo duro da economia mainstream. Para isso contribuíram, de forma importante, os prêmios Nobel conferidos a Ronald Coase em 1991 e a Douglass North em 1993, que ajudaram a convencer os economistas mais influentes da corrente dominante de que havia chegado o tempo de incluir o ambiente institucional como uma dimensão endógena dos modelos econômicos. A proposição básica desses dois autores, desenvolvida por vários importantes seguidores como Oliver Williamson, era a de que as instituiçôes, como, por exemplo, as leis que regulamentam o direito de propriedade, se desenvolviam para reduzir os custos envolvidos nas transações, principalmente os derivados da predisposição inata das pessoas a romper contratos se isso lhes for vantajoso. Mais recentemente, tem-se constatado que existem situações, denominadas de dilemas sociais, em que além de reduzir custos de transação as instituições são criadas para resolver problemas de ação coletiva. Tais problemas em geral não são passíveis de serem solucionados por negociações entre as partes envolvidas, requerendo a mobilização política de grupos de interesses. A implicação desta constatação é que a economia neo-institucionalista só poderá dar explicações satisfatórias dos grandes problemas sociais e econômicos se adotar uma abordagem de economia política, incluindo uma segunda dimensão em seu arcabouço teórico, além dos custos de transação; a economia política neo-institucionalista, assim, como será mais adequadamente justificado à frente, pode ser definida como a resultante da combinação da economia dos custos de transação e da teoria da ação coletiva. O presente trabalho objetiva mostrar como isso vem sendo feito, no campo teórico, ilustrando a teoria com uma análise dos eventos dramáticos que culminaram com o suicídio de Getúlio Vargas, processo este que se considera insuficientemente explicado pelas interpretações tradicionais. As principais questões, que se acredita que a teoria apresentada possa contribuir para explicar de forma mais satisfatória, são a seguir apresentadas.

Costuma-se atribuir à decisão do suicídio de Vargas um elevado grau de racionalidade. Acuado por inimigos implacáveis, ele teria desferido um golpe genial que, contra todas as expectativas, lhe concedeu uma última vitória política. Mas se ele ainda tinha tanto apoio popular, como as manifestaçóes posteriores demonstraram, por que ele não foi capaz de mobilizá-lo enquanto vivo? Como foi possível, por outro lado, que adversários tão viscerais o tivessem feito, isto é, logrado conquistar a opinião pública para a sua causa? Duas explicações possíveis são as de que a opinião pública da época seria irracional e volúvel, ou que os protagonistas da cena política tenham sido extraordinariamente incompetentes em usar essa opinião pública para apoiar seus projetos políticos, mas isto seria simplificar demais as coisas. Se Vargas sempre havia sido tão racional e habilidoso politicamente, como poderia ter se tornado de repente tão 
inepto? Admitir, por outro lado, que a opinião pública era completamente volúvel e suscetível a adotar comportamentos irracionais significaria dar um peso excessivo a elementos de cunho emocional, que certamente estiveram presentes, mas não foram, como se argumentará a seguir, fatores decisivos no processo.

A explicação que se dará aqui não depende de hipóteses pouco plausíveis sobre o grau de racionalidade dos políticos ou da própria opinião pública. Ao contrário, será sugerido ser plausível que o evento dramático do suicídio de Getúlio Vargas seja o momento culminante de um processo em que os principais agentes envolvidos tenham agido de forma racional, embora insuficientemente informada sobre as circunstâncias. Isto significa que cada agente provavelmente fez o melhor uso das informaçôes disponíveis, por exemplo sobre as intenções e o "poder de fogo" dos seus adversários. A insuficiência de informações decorreu de outra fonte, a saber, da incapacidade de prever o comportamento coletivo dos grupos de indivíduos envolvidos. Em particular, se mostrará que em momentos de crise, como o que se irá estudar, proliferam comportamentos oportunistas, que destroem supostamente sólidas alianças políticas ou impedem que elas venham a exercer a influência que potencialmente se achava que elas tinham.

O texto está organizado da seguinte forma. Na seção 1 apresenta-se o referencial teórico, enfatizando o argumento decisivo do trabalho de que coalizões de indivíduos tendem agir como indivíduos isolados quando se trata da provisão de bens públicos, isto é, têm incentivo para atuar como free riders. Assim, tais coalizões, organizadas ou não em organizações formais como os partidos políticos, privilegiam seus interesses particulares em prejuízo da eficiência econômica, tornando a vida política da sociedade mais conflituosa. Na seção 2 procura-se aplicar esse esquema interpretativo à conjuntura política que levou ao final dramático da era Vargas; a idéia central é a de que, como grandes grupos são mais difíceis de se organizar politicamente do que pequenos grupos, a decisão de Vargas de enfrentar seus adversários apoiado apenas no povo ("eu voltarei como um lider de massas e não como um lider politico" - havia avisado ele antes de sua volta triunfal ao poder em 1950) foi, afinal de contas, equivocada. Ele superestimou a força política das organizações populares e subestimou o "estrago" político que pequenos grupos bem organizados poderiam fazer em sua base de poder. A última seção conclui o trabalho, sugerindo que a teoria exposta possa ser útil para ajudar a compreender outras conjunturas da história política brasileira.

Alerta-se o leitor, para finalizar esta introdução, que este não é propriamente um trabalho historiográfico, mas um ensaio em economia política. Assim, optou-se por deixar de fazer uma pesquisa de fontes em níveis aceitáveis para o historiador profissional, embora em trabalho de maior fôlego isso fosse certamente inadequado, e por concentrar a análise no nível teórico. Espera-se que os insights que o presente trabalho 
venha eventualmente produzir possam encorajar contribuições capazes de reduzir suas deficiências do ponto de vista historiográfico.

\section{PEQUENOS E GRANDES GRUPOS E A AÇÃO POLÍTICA: A NOVA ECONO- MIA INSTITUCIONAL E A TEORIA DA AÇÃO COLETIVA}

A teoria da ação coletiva constitui-se, por assim dizer, na dimensão política da nova economia institucional (NEI). A versão tradicional da NEI, baseada no conceito-chave de custos de transação, enfatiza o papel das negociações entre indivíduos como fonte do processo de evolução institucional, ${ }^{1}$ mas deixa de considerar um aspecto crucial no processo de formação das instituições que não se relaciona aos custos de transação. A contribuição fundamental de Mancur Olson, formulador original da teoria moderna da ação coletiva, foi demonstrar que, diferentemente da famosa proposição neo-institucionalista conhecida como Teorema de Coase, mesmo em um mundo onde os custos de transação fossem negligíveis, as instituições seriam importantes para explicar o desenvolvimento econômico. $\mathrm{O}$ argumento formulado inicialmente por ele (1965) e desenvolvido mais recentemente por Hardin (1982) e Bates (1995) é exposto a seguir.

Muitas vezes é impossível alcançar soluções cooperativas por negociação. Existem situaçôes, definidas como dilemas sociais, em que, por razões associadas, por exemplo, à existência de externalidades, as sociedades são incapazes de alcançar configurações eficientes no sentido paretiano, porque indivíduos e firmas, agindo racionalmente, irão engajar-se excessivamente na produção de bens que geram externalidades negativas e deixarão de produzir bens e serviços que geram externalidades positivas, esperando

1 Os desenvolvimentos teóricos obtidos pela nova teoria institucional em sua versão tradicional desdobram-se em duas direções principais complementares. Em uma delas, a preocupação central é analisar as mudanças no meio ambiente institucional geral das economias, isto é, no conjunto de regras políticas, sociais e legais fundamentais, por exemplo, nas regras regulando os direitos de propriedade e os contratos, que estabelecem a base para a produção, troca e distribuição de mercadorias em uma certa sociedade. A segunda corrente, por sua vez, ocupa-se basicamente do estudo da interação entre as unidades econômicas nos processos de produção, troca e distribuição, enfatizando a forma como surgem e se desenvolvem instituições que asseguram a cooperação entre as unidades econômicas nesses processos. A primeira dessas correntes deriva fundamentalmente dos trabalhos de Douglass North, cuja principal preocupação é entender de que forma as macroinstituições de um país afetam seu desempenho econômico no longo prazo, identificando aquelas que são mais propícias ao desenvolvimento econômico e mostrando por que em alguns países as instituições mais adequadas não são adotadas, eternizando uma situação de subdesenvolvimento econômico; alguns dos trabalhos recentes mais representativo a respeito são North $(1996,1994,1991)$. A segunda corrente, que versa basicamente sobre o comportamento de firmas e indivíduos, origina-se com o famoso trabalho de Ronald Coase (1937), mas só vem a frutificar mais tarde com base nas contribuições de Oliver Williamson (1996, 1985, 1979). O objetivo principal dessa corrente é entender como se formam e como se modificam as estruturas de governança para determinadas transações; isto é, o conjunto de instituições que permite que um determinado tipo de transação se realize de forma contínua. 
que outros o façam por eles. Nessas condições, o teorema de Coase deixaria de ser válido não apenas porque existem custos de transação que impedem que as pessoas negociem de forma a alocar privadamente os custos implicados pelas externalidades. A razão principal de por que as instituições que garantiriam a eficiência social não são em geral adotadas é que essas instituições não interessam a grupos de indivíduos capazes de se organizar politicamente para se beneficiar de comportamentos do tipo free rider e rent seeker. As negociações que os novos economistas institucionais supõem serem a fonte do processo de evolução institucional se dão, em outras palavras, dentro de estruturas formadas na arena política.

Para esclarecer melhor este ponto crucial para o argumento do trabalho considerem-se as duas situações de interação social abaixo, representadas pela estrutura de um jogo iterado por tempo infinito e de soma maior que zero. As letras em cada célula representam os pay offs de cada agente para cada estratégia, de modo que se, por exemplo, ambos os agentes cooperam um com o outro, ambos recebem como prêmio o valor (financeiro ou medido em termos de alguma outra unidade de utilidade) a.

\begin{tabular}{|c|c|c|c|}
\hline \multicolumn{4}{|c|}{ Situação 1} \\
\hline \multirow{6}{*}{ Agente 1} & & \multicolumn{2}{|c|}{ Agente 2} \\
\hline & & Coopera & Não coopera \\
\hline & Coopera & aа & $b c$ \\
\hline & & & \\
\hline & Não coopera & $\mathrm{cb}$ & dd \\
\hline & \multicolumn{3}{|c|}{$a>d, d<c<a$ e $b<d$} \\
\hline \multicolumn{4}{|c|}{ Situação 2} \\
\hline \multirow{6}{*}{ Agente 1} & & \multicolumn{2}{|c|}{ Agente 2} \\
\hline & & Coopera & Não coopera \\
\hline & Coopera & aа & $b c$ \\
\hline & & & \\
\hline & Não coopera & $\mathrm{cb}$ & $\mathrm{dd}$ \\
\hline & & $a>d, c>a$ e & \\
\hline
\end{tabular}

Na primeira situação, pode-se inferir que há uma boa probabilidade de que a cooperação entre os agentes se desenvolva espontaneamente à medida que estes percebam os benefícios mútuos que podem ser alcançados e que consigam coordenar suas ações para superar os obstáculos existentes à ação cooperativa. Observe-se, por exemplo, que embora a solução cooperativa seja um equilíbrio de Nash, a confiança mútua é um pré-requisito indispensável ao processo, visto que se apenas um dos agentes decidir cooperar ele terá seu pay off reduzido em relação à situação inicial, enquanto que o outro terá seu pay off aumentado. É razoável afirmar que a nova economia institucional 
em sua versão custos de transação enfatiza esse tipo de situação, ou seja, as condições necessárias para que os agentes superem ou obstáculos macroinstitucionais à cooperação (como nos trabalhos de Douglass North) ou a resistência à cooperação no nível das estruturas de governança (como na obra de Williamson e seguidores).

Mas a segunda situação, que representa o dilema do prisioneiro clássico, é bem diferente. A estratégia dominante para ambos os agentes é não cooperar, e assim a cooperação não deixa de ocorrer simplesmente porque os agentes não consigam coordenar suas ações, devido, por exemplo, aos elevados custos de transação envolvidos, mas porque, se decidirem cooperar unilateralmente, o outro terá incentivos para deixar de cooperar. Isto é, a solução cooperativa não é um equilíbrio de Nash, e assim não tem a estabilidade da solução anterior. Para confirmar este resultado, observe que o pay off do agente 1 será maior se ele não cooperar quando o agente 2 cooperar do que se ele agir com reciprocidade (c contra a). Em grandes grupos, isto significa que será uma estratégia racional tentar "pegar carona” nos benefícios da cooperação em vez de contribuir para alcançar esta situação. Nessas condições, em um mundo em que os agentes agem racionalmente (da forma como se define no presente trabalho), a estratégia dominante para cada agente será não cooperar (atuando como free rider ou rent seeker) e o equilíbrio ineficiente em termos de Pareto da não cooperação prevalecerá. Estudos mais recentes realizados por teóricos de jogos (ver, por exemplo, Axelrod, 1997, cap. 1) e autores neo-institucionalistas (ver, entre outros, Putnan, 1993 e Ostrom, 2000) têm demonstrado que em grupos relativamente pequenos, em que os agentes interagem repetidamente por longos períodos de tempo, esse tipo de obstáculo à cooperação pode ser superado por meio da confiabilidade interpessoal acumulada pelo grupo ou comunidade; para grupos maiores, como os que constituem a unidade de análise da ciência política e da macroeconomia, entretanto, não é razoável esperar que isso aconteça. ${ }^{2}$ Esta, como se mostrou, já havia sido a principal conclusão do texto seminal de Olson de 1965.

Em texto posterior (1982), ele expandiu esse argumento central para descrever a lógica das organizações políticas. A idéia básica é a de que, contra-intuitivamente, em geral a influência política de pequenos grupos é maior do que a dos grandes, porque os indivíduos participantes dos primeiros têm maiores incentivos para atuarem politica-

2 Em importante estudo sobre sistemas de utilização de recursos comuns (Common-Pool Resources ou CPRs), por exemplo, Elinor Ostrom (1994, p. 319) enfatiza que: "In CPR dilemmas where individuals do not know one another, cannot communicate effectively, and thus cannot develop agreements, norms and sanctions, aggregate predictions derived from models of rational individualism a non-cooperative game receive substantial support. These are sparse environments and full rationality appears to be a reasonable assumption in them. We would advise anyone in field situations closely matching these conditions to expect others select strategies that generate aggregate outcomes close to Nash equilibrium and to act accordingly. In large-scale CPR dilemmas where communication opportunities for all parties are extremely limited, such an expectation means that others are likely to overappropriate, underprovide, and/or engage in high levels of conflict about assignment and technological externality problems." 
mente. Pessoas participantes de grandes grupos sabem que os benefícios que poderão auferir de sua ação política serão pequenos, pois os eventuais ganhos serão divididos por muitos. Assim, é racional não se envolver em demasia, não apenas em termos de cooperação em dinheiro, mas também de outro tipo que envolva mesmo um nível limitado de sacrifício pessoal, como o requerido para estudar cuidadosamente as estratégias e os resultados possíveis de cursos de ação alternativos disponíveis. Do ponto de vista de cada indivíduo existe, portanto, um nível ótimo de informação a ser obtido, isto é, um nível ótimo de ignorância em assuntos como a política e a economia de um país. Em pequenos grupos, a situação é inversa: como os benefícios, se alcançados, representarão ganhos expressivos para os participantes, a disposição de participação na ação política bem como os níveis ótimos de sacrifício pessoal e de compromisso com a ação política serão em geral maiores.

Essa é a explicação de por que grupos de consumidores, de pagadores de impostos e de desempregados dificilmente se organizam: os benefícios esperados, por exemplo, de um boicote a determinados produtos serão provavelmente pequenos, dependendo da participação do item boicotado no orçamento dos consumidores. E, afinal, é perfeitamente legítimo supor que a importância da ação de cada indivíduo, seja consumindo ou deixando de consumir o produto, será em geral reduzida, o que os induz a não cooperar com a ação coletiva na suposição de que outros o farão, o que seria suficiente para alcançar os resultados pretendidos. Evidentemente, o que é racional do ponto de vista individual não o será da perspectiva do grupo como um todo: os sacrifícios necessários não serão feitos e os resultados não serão alcançados.

Grupos como o de grandes industriais de um determinado setor econômico, de trabalhadores urbanos sindicalizados, militares e políticos são comparativamente mais fáceis de se organizarem para a ação política e assim orientarem a distribuição de recursos da sociedade em seu benefício. Mas não surgem espontaneamente. Mesmo grupos pequenos demoram a se organizar e só o fazem em condições favoráveis. Eventos exógenos do ponto de vista dos novos grupos, como revoluções políticas e mudanças drásticas nas condições econômicas da sociedade, são em geral necessários para fornecer as condições favoráveis para a formação de coalizões e para o surgimento de organizações para a ação coletiva.

Tais organizações tendem a ter uma atuação semelhante à dos indivíduos isolados no que tange à provisão de bens públicos (bens que atendem a um grande número de pessoas que não podem ser excluídas de seu uso, mesmo não contribuindo para sua provisão). Não terão incentivos para contribuir com sua provisão, embora tenha incentivo para obter uma parcela maior do bem público para seus membros, mesmo que as medidas necessárias para fazer isso não contribuam para aumentar o "bolo" a ser dividido pela sociedade. Assim, em geral, as organizações tenderão a reduzir a 
eficiência com que a economia opera e tornam a vida política mais conflituosa. Isto é mais verdadeiro quanto mais excludentes forem as organizações, pois organizações que incluem um maior número de pessoas tendem a ser mais favorecidas pela prosperidade geral. Ir-se-á mostrar na próxima seção que a era Vargas foi uma época especialmente favorável ao surgimento de pequenos grupos organizados que acabaram por tornar a política extremamente conflituosa a partir da década de 1950, culminando com o episódio dramático do suicídio.

\section{A ERA VARGAS}

Por não haver resultado da vitória de um projeto econômico ou mesmo político específico, embora certamente tenha sido um divisor de águas na evolução das instituições brasileiras, o regime político que se consolida a partir da Revolução de 1930 não terá fundações firmes nos grupos sociais que dela participaram. ${ }^{3}$ Para construir sua base de sustentação, Vargas teve assim de redefinir a estrutura de incentivos da economia para contemplar os novos agentes políticos que começaram a pesar na balança de poder a partir de 1930, sem alienar completamente os grupos tradicionais associados à cafeicultura, dos quais a economia brasileira ainda continuava a depender para funcionar. Como esses dois objetivos eram inconsistentes no longo prazo (sua compatibilidade do curto prazo requeria uma aceleração das emissões monetárias e inflação), em algum momento o governo teria que recorrer aos grupos mais organicamente ligados ao regime para implementar as medidas de estabilização necessárias. Se Vargas viesse a se mostrar incapaz de mobilizar esses grupos no momento necessário, ou porque eles de fato não estivessem comprometidos com seu projeto político ou por razões ligadas à lógica da ação coletiva, a aliança política em que ele se apoiava se esgarçaria. Para compreender a dinâmica desse processo, tal como ele ocorreu na era Vargas, é necessário rever rapidamente como essa aliança se formou nos primeiros anos desse período.

3 A expressão clássica de Francisco Weffort - "Estado de Compromisso" - reflete esta situação, em que a solução do conflito que culminou com a Revolução de 1930 emergiu, no sentido de não ser possível identificá-la claramente com estratégias definidas "ex-ante" por qualquer dos grupos políticos e econômicos envolvidos. Nas palavras de Boris Fausto (1976, p. 113): "Vitoriosa a revolução, abre-se uma espécie de vazio de poder, por força do colapso politico da burguesia do café e da incapacidade das demais fraçôes de classe para assumi-lo, em caráter exclusivo. O Estado de Compromisso é a resposta para esta situação. Embora os limites da ação do Estado sejam ampliados para além da consciência e das intenções de seus agentes, sob o impacto da crise econômica, o novo governo representa mais uma transação no interior das classes dominantes, tão bem expressa na intocabilidade sagrada das relações sociais no campo. Mas o reajuste, obtido após um doloroso processo de gestação ... significa uma guinada importante no processo histórico brasileiro. A mudança das relaçóes entre o poder estatal e a classe operária é a condição do populismo; a perda do comando político pelo centro dominante, associada à nova forma de Estado, possibilita, a longo prazo, o desenvolvimento industrial, no marco do compromisso; as Forças Armadas tornam-se um fator decisivo como sustentáculo de um Estado que ganba maior autonomia em relação ao conjunto da sociedade." 
A política econômica do governo Vargas desde o início em 1930, como talvez sempre aconteça, foi inteiramente subordinada aos seus objetivos políticos. O principal deles era naturalmente a consolidação de seu poder político. A reorientação da matriz de incentivos da economia em favor da industrialização, com a criação de novos mecanismos de financiamento, como o controle dos empréstimos do Banco do Brasil a juros baixos e o estabelecimento de taxas múltiplas de câmbio e controle de importaçôes, refletiu, assim, mais do que uma opção por redefinir o eixo dinâmico da economia, uma estratégia de minar as fontes tradicionais de poder político da República Velha. ${ }^{4}$ É interessante observar a esse respeito que a constituição de um poder centralizado não era um objetivo das elites que apoiaram a revolução de 1930. O partido Democrático Paulista, por exemplo, que havia apoiado a revolução de outubro foi o primeiro a romper com a coalizão que havia levado Vargas ao poder, aliando-se ao Partido Republicano Paulista, que por razões óbvias estava disposto a obter vingança contra os que haviam impedido a posse de Júlio Prestes. Não há evidência alguma que essa estranha aliança tenha se formado por uma reorientação ideológica de qualquer uma das partes. Ao contrário, os constitucionalistas liberais do Partido Democrático decidiram liderar a Frente Única Paulista no movimento que culminou com a revolução de 1932 porque não conseguiram obter o poder político que seus rivais do PRP sempre tinham tido durante a República Velha. ${ }^{5}$

De certo modo a revolução de 1932 é um último espasmo do sistema político anterior. Os grupos políticos lutavam pela supremacia política, esperando ocupar o espaço político deixado vago pela derrota da fração da elite política que havia dado as cartas durante a República Velha. Mas enquanto a estratégia da oposição pressupunha manter intacta a estrutura tradicional de poder, a de Vargas colocava em movimento forças que minavam as bases dessa estrutura. $\mathrm{O}$ apoio à industrialização como estratégia fundamentalmente política, por exemplo, aumentava o peso dos interesses urbanos na equação política, à medida que apenas pelo crescimento da atividade industrial o número de trabalhadores urbanos em geral alfabetizados e, portanto, em condições de votar, automaticamente aumentava. As classes médias, por outro lado, embora ainda pudessem ser seduzidas pelas propostas dos constitucionalistas liberais (e continuarão sendo uma base importante para as bandeiras que eles, visando a seus próprios objetivos políticos, continuarão a levantar até meados da década de 1960), não eram um grupo que pudesse ser organizado como o dos trabalhadores recém-sindicalizados ou mesmo dos industriais que agora tinha seus interesses colocados em primeiro plano pela política econômica. E isso porque seus interesses econômicos não eram suficientemente homogêneos nem estava claro exatamente o que, em termos econô-

4 Não parece justificado supor, como faz Fonseca (2003), que essas mudanças institucionais reflitam um propósito industrializante do governo. Elas não são subprodutos da defesa dos interesses cafeeiros, mas também não são itens de um programa consciente de industrialização; trata-se de medidas implementadas por objetivos políticos e não econômicos (a respeito, ver Skidmore, 1992, p. 56).

$5 \quad$ Ibid p. 35. 
micos, resultaria de benéfico de um compromisso mais decidido com a plataforma dos constitucionalistas.

Não, evidentemente, que os sindicatos recém-criados representassem adequadamente os interesses dos trabalhadores; na verdade, eles foram muito mais, é claro, um instrumento de legitimação do governo Vargas do que uma suposta conquista dos movimentos populares. Mas não há dúvidas de que para exercer esse papel, concessões como a fixação dos primeiros salários mínimos durante o Estado Novo, por exemplo, tiveram de ser feitas. E isso já era muito significativo para as massas urbanas em comparação com o padrão que prevaleceu durante a República Velha.

A mudança do eixo dinâmico da economia, para usar o termo consagrado de Celso Furtado, foi ao que tudo indica um processo espontâneo induzido em parte pela redução dramática da capacidade para importar nos anos 1930. Mas mais do que um mero movimento reflexo, a industrialização emergiu, no sentido da moderna teoria da complexidade. Embora não fosse projeto político de nenhuma das forças políticas relevantes da época, ela foi uma conseqüência imprevista do conflito essencialmente político que ocorria no ponto de bifurcação histórico que marcou a transição para o Brasil moderno.

Os grupos políticos que irão se opor na luta pelo poder daí em diante operarão em um meio ambiente social incomparavelmente mais complexo do que o que havia existido até 1930. Passado o (longo e penoso) interregno do Estado Novo, em que as novas forças políticas puderam passar a se expressar politicamente por meio do voto, as linhas gerais do movimento político, em termos muito gerais, foram as seguintes.

A eleição de Dutra foi quase como que um entreato do drama que seria encenado realmente na primeira metade da década de 1950, mas esboça o cenário que irá se consolidar a seguir. O fato de o presidente ter sido eleito com maciça votação, $55 \%$ dos votos, a despeito de sua total falta de carisma (os dirigentes do PSD tentaram até mesmo substituí-lo a três meses da eleição por não considerar sua candidatura viável), e do apoio da classe média ao candidato da UDN, brigadeiro Eduardo Gomes, revela que a máquina política montada por Vargas estava mais forte do que nunca e que sua deposição tenha sido consequiência de uma conjuntura política momentânea e não estruturalmente desfavorável. Os políticos de oposição aparentemente confiavam que o apoio da classe média era a mesma coisa que apoio popular, o que obviamente não era verdade. Embora o fator decisivo da eleição tenha sido a máquina eleitoral do PSD, cuja base era ainda essencialmente rural, a votação expressiva obtida pelo PTB e, surpreendentemente, pelo PCB nas eleiçóes casadas para o Congresso (quase 20\% do total) indicam que os sindicatos e os partidos organizados por Vargas falavam mais alto do que o movimento de opinião pública que o havia derrubado do poder. 
As mudanças econômicas acontecidas na década de 1930 tinham criado, de fato, novas forças políticas, especialmente uma grande massa de eleitores urbanos. Mas essa massa, embora em condições de fazer o processo político pender a seu favor, não estava organizada para fazê-lo. Essa falta de organização, entretanto, não decorria, ao que tudo indica, de um amadurecimento político insuficiente. Tudo levado em conta, não havia qualquer razão para que um trabalhador urbano médio votasse no candidato da oposição. O programa de Eduardo Gomes enfatizava os aspectos jurídicos da democratização, mas era para dizer o menos dúbio em relação à industrialização, que era fundamental para a manutenção do emprego e da renda nas cidades. Embora não se opusesse diretamente ao seu prosseguimento, na prática, ao propor uma volta ao laissez-faire econômico, propunha medidas que a inviabilizariam. Não chegavam a propor o desmanche da legislação previdenciária e nem da estrutura sindical, mas não deixa de ser significativo que, na campanha da próxima eleição, o brigadeiro tenha repudiado a lei do salário mínimo. ${ }^{6}$

A vitória de Dutra foi assim, mesmo sem Vargas, a vitória das forças que ele ajudou a impulsionar em seu primeiro governo. $\mathrm{O}$ fato de que a força de maior peso nessa eleição tenha sido ainda a maquina eleitoral-rural não é, quando se analisa a questão como propomos aqui, contraditório. Revela apenas que a vitória da estratégia de Vargas foi tão completa que não restou alternativa às antigas elites, antes na oposição, que não apoiar o grupo político de Getúlio Vargas, como iria ficar totalmente explícito na eleição seguinte.

Apoiado na aliança que elegeu Dutra, acrescida do PSP de Ademar de Barros, Vargas foi eleito facilmente em outubro de 1950. A oposição udenista, na figura novamente de Eduardo Gomes, e novamente com uma plataforma liberal, ficou em segundo lugar, com menos de $30 \%$ dos votos. Como em menos de 4 anos ela foi capaz de encurralar o presidente a ponto de levá-lo ao suicídio?

Do ponto de vista político, a aliança com Ademar de Barros por haver sido fundamental para a eleição ao canalizar a opinião pública de classe média paulista, que não se sentia satisfatoriamente contemplada pelos programas dos partidos tradicionais, comprometia, pelo menos teoricamente, Vargas com o projeto político pessoal de Ademar de tornar-se presidente na próxima eleição. O PSD, embora houvesse indicado candidato próprio à eleição, havia na prática apoiado Vargas nos principais Estados e assim fazia jus a parcela importante do poder, mas essa participação já estava, por assim dizer, institucionalizada e não colocava nenhuma nova dificuldade política ao esquema de poder varguista; o PTB finalmente, embora estivesse crescendo rapidamente, não tinha tido um peso muito importante na eleição presidencial, a não ser no Distrito Federal e no Rio Grande do Sul, onde provavelmente Vargas venceria

$6 \quad$ Ibid p. 106. 
de qualquer modo, apoiado em seu prestígio pessoal. Com exceção da ascensão de Ademar de Barros, portanto, nenhuma nova variável foi adicionada à equação política pós-eleitoral; mesmo a dívida com Barros não era um passivo político pesado para um político habituado a administrar ambições e vaidades individuais com maestria.

Do ponto de vista econômico, a situação que Vargas herdou de Dutra era relativamente folgada. A alta nos preços do café a partir de 1949 havia permitido um aumento das reservas internacionais, que iria permitir aos empresários brasileiros aumentar expressivamente as importaçôes de bens de capital e produtos intermediários essenciais para a aceleração do ritmo de crescimento econômico. Mas as importações cresceram acima do esperado, fazendo com que a pressão sobre o balanço de pagamentos alcançasse um nível inédito desde os anos de 1940. Em parte por causa da crise do Balanço de Pagamentos, mas principalmente devido à inelasticidade da oferta interna de bens de consumo de massa a inflação, medida pelo índice do custo de vida, se acelerou para $21 \%$ ao ano em 1952 (o dobro do índice de 1951). Vargas respondeu a essas dificuldades em parte com medidas de cunho nacionalista, como o estabelecimento do decreto que estabelecia um teto de $10 \%$ para remessa de lucros; entretanto, essas medidas não chegaram a ser aplicadas na prática, porque os preços das exportações voltaram a melhorar em 1952. Quanto à inflação, o problema era mais grave. Se no caso do Balanço de Pagamentos o discurso nacionalista de Vargas era capaz de unir a sociedade, o combate à inflação exigia políticas que necessariamente alterariam a distribuição de renda. O grupo que mais sofria com a inflação era o dos trabalhadores urbanos cujos salários estavam atrelados ao salário mínimo, que havia sido reajustado pela última vez em 1951. Em fins de 1953, a situação se tornou insustentável e Vargas anunciou o plano de estabilização preparado pelo ministro da Fazenda Oswaldo Aranha, que continha medidas ortodoxas como restrição ao crédito e controles cambiais, que na prática implicavam uma desvalorização substancial da moeda. Mas essas medidas requeriam tempo para funcionar. Enquanto isso Vargas aumentou o tom do discurso nacionalista e a inflação continuou a se acelerar. Um novo fator de tensão econômica foi o boicote norte-americano ao café brasileiro, devido ao alto preço sustentado pelo governo pela retenção de estoques.

É nesse quadro econômico difícil que Vargas começa a se preparar para enfrentar as eleições parlamentares e para os governos estaduais, assim como para a sua própria sucessão. Apenas tendo em mente que esse objetivo político se sobrepunha a todos os outros é que podemos compreender a sucessão de eventos ocorridos entre janeiro e agosto de 1954. O Ministro do Trabalho João Goulart, nomeado em julho de 1953, sob intensas suspeitas da elite econômica e da própria classe média, propôs em fevereiro de 1954 um aumento de $100 \%$ do salário mínimo, o que eliminaria qualquer chance de o Plano Aranha funcionar. O despropósito dessa medida era tão evidente que Vargas foi obrigado, por pressão da imprensa e principalmente do Exército, a 
demitir seu ministro no mesmo dia em que este divulgou a proposta. ${ }^{7}$ Ao mesmo tempo deu a entender que o aumento do salário mínimo atingiria no máximo $42 \%$ e acentuou o seu discurso nacionalista, o que contribuiu para acalmar os militares e a opinião pública de classe média.

O fracasso da tentativa da UDN de afastar o presidente, em razão de uma suposta conspiração com o peronismo para implantar uma ditadura no Brasil, foi um sinal claro de que a situação política ainda estava sob controle em abril de 1954. Mas então, inesperadamente, contrariando a opinião de todos os seus assessores econômicos, Vargas decretou o aumento de salário mínimo de 100\% que o havia levado a demitir seu Ministro do Trabalho. Por quê?

Um dos instrumentos fundamentais do Plano Aranha era a Instrução 70 da SUMOC, implantada em outubro de 1953, que instituía um sistema de taxas múltiplas de câmbio. Essa medida na prática permitia a implementação de amplas desvalorizações cambiais, simultaneamente à manutenção de um controle seletivo de importações, segundo critérios de essencialidade. ${ }^{8}$ Estava claro desde o início, entretanto, que a implementação da Instrução 70 elevaria os custos de produção da indústria, sem elevar o grau de proteção efetiva da economia, visto que, na média entre importações mais e menos essenciais, a taxa de câmbio continuaria aproximadamente a mesma. ${ }^{9}$ À elevação dos custos de produção somou-se a contração do crédito para a atividade econômica nos últimos meses de 1953, que embora tenha voltado a se expandir em 1954, forçou uma expressiva elevação da taxa de inflação já em 1953.

Dois setores da população que tinham sido importantes para a eleição de Vargas em 1950 (principalmente em São Paulo) foram profundamente afetados pelo programa de estabilização: os industriais, que tiveram que arcar com uma redução de sua margem de lucros, além da redução da despesa pública em obras de infra-estrutura, e a população urbana, em geral mais afetada pela elevação dos índices de custo de vida. Um terceiro setor importante também foi afetado, mas por fatores exógenos. A princípio, a cafeicultura foi favorável à Instrução 70, já que esta gerava uma desvalorização da taxa de câmbio para o café, mas o boicote dos consumidores americanos ao café brasileiro em 1954 reverteu o humor dos cafeicultores. As exportações caíram em cerca de 5 milhões de sacas em 1954 em comparação com o ano anterior, e isso foi atribuído, não sem boa dose de razão, a uma política irresponsavelmente dura de sustentação dos preços do café.

7 O porcentual necessário para repor o pico do reajuste anterior era de cerca de 53\%. (Vianna, 1992, p. 144).

8 A discussão a partir daqui, a não ser quando mencionado, se baseia em Vianna (1987).

9 Ibid p. 106. 
Já nos primeiros meses de 1954, portanto, havia pressões por todos os lados para que o governo revertesse sua política de austeridade, que ele mal chegara a começar a implementar. Foi o que ele acabou fazendo, aumentando expressivamente, por meio do Banco do Brasil, o crédito para os governos estaduais e para a atividade econômica nos oito meses de gestão de Oswaldo Aranha à frente do Ministério da Fazenda, em 1954.

É nesse quadro de insatisfação generalizada com a política econômica que o aumento do salário mínimo de maio é decretado. O impacto negativo dessa medida foi o combustível (até certo ponto inesperado) para que a oposição política se reavivasse. Os setores empresariais, que haviam sido momentaneamente acalmados pela expansão do crédito, passaram inequivocamente para a oposição; o sindicato das Indústrias de Fiação e Tecelagem do Rio e Janeiro, por exemplo, expressando a irritação dos interesses industriais com Vargas, chegou a impetrar mandato de segurança contra a medida. ${ }^{10}$ Os militares e a classe média, não beneficiados pelo reajuste do salário mínimo, mas diretamente afetados pelo aumento de inflação que a medida claramente provocaria, também se tornaram um público mais do que suscetível ao discurso oposicionista.

O único setor que apoiou a medida foi o dos trabalhadores urbanos, mas sua capacidade de dar suporte político ao governo era limitada. De maneira surpreendente, dada a sua perspicácia política e a compreensão profunda da psicologia das massas, Vargas pareceu acreditar que a percepção dos benefícios que sua política gerava para os trabalhadores assim como o perigo que a oposição representava para a continuidade dessa política seriam suficientes para levá-los a cerrar fileiras ao seu lado, dando-lhe a vitória nas eleições de outubro e, quem sabe, a seu candidato nas eleições presidenciais de 1955. ${ }^{11}$ Provavelmente essa foi a razão de não ter se esforçado muito para fortalecer o PTB para as eleições de outubro e nem ter colocado à frente do Ministério do Trabalho, em substituição a João Goulart, uma figura capaz de mobilizar, de fato, os sindicatos operários, então sob o controle do Ministério, para uma ação política mais efetiva. ${ }^{12}$

O que Vargas deixou de perceber foi que, diferentemente dos grupos políticos de oposição política, os trabalhadores urbanos tinham incentivos para agir como free riders: para que se comprometer se o benefício já fora conseguido e se, mesmo que

$10 \quad$ Ibid p. 165

11 Embora, como lembra Vianna (1992, p. 149), seja discutível que Vargas acreditasse realmente que além de garantir-lhe a vitória nas eleições, o apoio popular por si só pudesse ser a coluna que sustentaria seu governo. Mas a oposição tampouco tinha elementos para acreditar que o que estava em jogo era muito mais que o resultado nas eleiçôes seguintes; é discutível que lhe interessasse naquele momento a deposição do presidente, mas certamente, se pudesse intuir o final trágico da crise, teria moderado seus ataques para evitar o enorme prejuízo político que o suicídio lhe causou.

12 Skidmore (1992, p. 174). 
houvesse perigo de ser retirado, a força do seu número em votos por si só seria capaz de conter os adversários? Afinal, o próprio Getúlio havia dito no famoso discurso em Petrópolis, em que anunciou o salário mínimo, que:

"...pelo voto podeis não só defender os vossos interesses, como influir nos próprios destinos da Nação. Como cidadãos, a vossa vontade pesará nas urnas. Como classe, podeis imprimir ao vosso sufrágio a força decisória do número. Constituis a maioria. Hoje estais com o Governo. Amanhã sereis o Governo."13

Ele estava errado. Mas não foi irracional. Apenas, ao que tudo indica, deixou de perceber que seus adversários tinham fortes razões para combatê-lo, arriscando a própria vida como supostamente fez Lacerda, enquanto que seus aliados, agindo também racionalmente, preferiram esperar para ver o que aconteceria em vez de agir em conjunto. Ou seja, embora tenha avaliado corretamente o apoio popular de que dispunha, provavelmente ignorou uma das lições básicas da teoria da ação coletiva que os grandes líderes políticos sempre intuíram: a de que o poder político potencial de grandes grupos dificilmente se materializa em ação política efetiva espontaneamente. O fato de o suicídio ter levantado tamanho clamor popular é uma evidência de que, se as instituições que representavam os trabalhadores pudessem ter sido adequadamente mobilizadas antes (o que não é provável do ponto de vista da teoria da ação coletiva), talvez os adversários de Vargas não tivessem conseguido acuá-lo da forma que o fizeram e a história pudesse ter seguido outro rumo. Mas não temos como sabê-lo.

\section{CONCLUSÃO}

A análise realizada baseou-se no pressuposto de que todos os agentes relevantes atuaram racionalmente na crise que culminou com o suicídio de Vargas. Tal pressuposto pode parecer irrealista, para não dizer tolo, se não se definir adequadamente o conceito de racionalidade empregado. Por comportamento racional objetivou-se conceituar o conjunto de ações voltadas para preservar o auto-interesse de cada agente relevante, os quais utilizam eficientemente as informações disponíveis em um ambiente permeado por incertezas de várias naturezas. Isso não quer dizer, obviamente, que cada agente faça realmente o melhor uso das informações. Quer dizer apenas que se for possível inferir que as conseqüências de determinadas ações eram passíveis de previsão com base nas informações que estavam em geral disponíveis na conjuntura que se está examinando, é injustificado supor que os agentes relevantes tenham deixado de levar essas informações em conta. Erros crassos e insensatez freqüentemente estão presentes

13 Ibid p. 171 .

Est. econ., São Paulo, 36(1): 181-199, jan-mar 2006 
nas decisões, mas se aprenderá pouco sobre o comportamento humano (a não ser que ele seja passível de cometer erros) se a análise se concentrar nesses aspectos, por mais cruciais que eles possam ter sido.

Quando se enfatiza o "componente" racional das decisões humanas, em vez das idiossincrasias dos tomadores de decisão, se está, na verdade, tentando esclarecer as circunstâncias em que indivíduos movidos pelo interesse próprio podem, por meio de suas decisões, produzir situações históricas comparáveis. Isto é, enfatizando o que o comportamento humano tem de comum (o fato de ser voltado para proteger o auto-interesse), pode-se, pelo menos em princípio, alcançar um grau de generalidade explicativa que o estudo detalhado das biografias individuais isoladamente não permite obter.

No caso de Getúlio Vargas, o perigo de sucumbir à tentação de fazer uma análise do último tipo é maior. A força de sua personalidade e a sua competência política têm levado autores importantes a ver inclusive o suicídio como um ato de cálculo político racional. Com este ato ele teria obtido uma última vitória sobre seus adversários políticos e impedido que eles implantassem com dez anos de antecedência o regime de $1964 .^{14}$

Não é essa a posição deste trabalho. Procurou-se mostrar no texto que as decisões políticas e econômicas presidenciais mais importantes tiveram em geral um objetivo político dominante: o de ampliar e consolidar o poder político de Vargas. A decisão de acelerar a industrialização do País, por exemplo, mais do que uma estratégia concebida e elaborada foi, em grande parte, uma conseqüência, ao que tudo indica, não antecipada das medidas políticas adotadas para enfraquecer a base política da República Velha. A centralização no Poder Federal das instituições e dos recursos financeiros permitiu o acesso ao crédito e aos investimentos governamentais por parte dos industriais, que assim se tornaram uma base importante para o projeto político de Vargas. O crescimento da atividade industrial e urbana em geral, por sua vez, aumentou o peso do voto dos trabalhadores urbanos, que irão ser uma base altamente receptiva ao discurso dos futuros líderes populistas, os quais terão um papel importante nos desdobramentos históricos futuros.

Usou-se um termo da moderna teoria da complexidade para definir esse processo: emergência. Diz-se que uma determinada conjuntura histórica emerge quando ela não pode ser explicada pela vitória do projeto de um grupo de interesses específico, mas da interação de estratégias individuais (no sentido de grupos de interesses) voltadas para atender aos objetivos políticos e/ou econômicos, cujas consequiências, entretanto, não eram passíveis de serem previstas nas estratégias iniciais.

14 Ver, por exemplo, Jaguaribe (1983, p. 21). 
Sugeriu-se neste texto que este conceito ajuda a compreender um pouco melhor processos históricos em que decisões perfeitamente racionais produzem resultados que historicamente não podiam ser previstos pelos agentes que as tomaram. Neste sentido, a decisão de Vargas de elevar o salário mínimo em 100\% em maio de 1954 pode ser considerada como um ato racional, ${ }^{15}$ mas que teve conseqüências altamente negativas para o presidente. Seu erro, se é que pode se chamar assim, foi ter sido incapaz de prever, com as informações disponíveis na época, que a lógica da ação coletiva o levaria a perder mais apoio efetivo do que poderia conquistar com essa medida. O desdobramento funesto dessa decisão equivocada, por outro lado, dificilmente pode ser considerado como um último lance magistral concebido racionalmente para derrotar seus adversários políticos. Não há, de fato, como sabê-lo; o raciocínio aqui desenvolvido baseia-se apenas, como não poderia deixar de ser, em hipóteses plausíveis sobre as razões que motivaram as decisões de Vargas e não em pretensas interpretações psicológicas. Parece, entretanto, legítimo especular que a decisão de suicidar-se refletiu mais, aqui sim, aspectos pessoais da personalidade presidencial, que, acuado por todos os lados, reagiu com o senso de honra do gaúcho da fronteira que só pode abandonar a peleja com a morte; isto ajuda a esclarecer que não se postulou no texto (obviamente) que todas as decisões humanas relevantes sejam tomadas por motivos racionais; muitas delas resultam de valores tão firmemente estabelecidos pela cultura em nosso subconsciente, como o próprio instinto de agir racionalmente está provavelmente inscrito em nossos genes.

Entender os aspectos racionais das decisões políticas tomadas por Vargas, entretanto, parece ser uma chave para compreender muito do que aconteceu nos anos seguintes, particularmente nos anos que antecederam o golpe militar de 1964. Parece que tanto Jânio Quadros como João Goulart cometeram o mesmo erro de Getúlio, superestimando o poder das massas não organizadas como base de poder político efetivo. E isso permitiu que grupos menores fossem bem-sucedidos na sempre arriscada tentativa de fazer uma revolução, porque, computando os custos e benefícios de suas ações, assim como provavelmente o fizeram os cidadãos comuns, pareceu racional apoiar ou pelo menos não se opor abertamente à derrubada do regime democrático.

Parece plausível que essa racionalidade inata do cidadão comum ajude a entender, como se pergunta um importante jornalista contemporâneo, ${ }^{16}$ “... onde estava [a força oceânica do getulismo] naqueles dias, desaparecida no turbilhão das expectativas atônitas e das perplexidades imobilizantes?"

15 A esse respeito, assinala Vianna (1987, p. 113-114): "Parece claro que o aumento do salário mínimo em $100 \%$ não pode ser funcionalmente explicado no contexto da politica econômica que as autoridades da área, com o aval de Vargas, procurava implementar. Isso não quer dizer, porém, que a decisão tenha sido errática e desprovida de racionalidade. Na verdade, o que Vargas procurava fazer eva criar condiçôes para enfrentar as eleiçôes parlamentares e para os governos estaduais previstas para outubro de 1954."

16 Jânio de Feitas, Folha de São Paulo, 24/08/2004, p. A7. 


\section{REFERENCIAS}

Axelrod, R. The complexity of cooperation - agent based models of competition and collaboration. Princeton, New Jersey: Princeton University Press, 1997.

Bates, R. Social dilemmas and rational individuals: an assessment of the new institutionalism. In: Harriss, J. et al., The new institutional economics and third world development. London: Routledge, 1995.

Coase, R. The nature of the firm. Economica, v. 4, n. 16, 1937. Reprinted in: Williamson, O.; Winter, S. (eds.), The nature of the firm - origins, evolution, and development. New York: Oxford University Press, 1991.

Fausto, B. A revolução de 1930. História e historiografia. 4a edição. São Paulo: Brasiliense, 1976.

Fonseca, P. D. Sobre a intencionalidade da política industrializante no Brasil na década de 1930. Revista de Economia Política, v. 23, n. 1 (89), jan/mar 2003.

Hardin, R. Collective action. Baltimore: Johns Hopkins University Press, 1982.

Jaguaribe, H. Impasse na democracia brasileira, 1951-1955. (Coletânea de documentos: prefácio). Rio de Janeiro: Editora de FGV, 1983.

North, D. Institutions, institutional change and economic performance. New York: Cambridge University Press, 1996. (First published 1990).

. Economic performance through time. The American Economic Review, v. 84, n. 3, June 1994.

. Institutions. Journal of Economic Perspectives, v. 5, n. 1, Winter 1991.

Olson, M. The rise and decline of nations. New Haven: Yale University Press, 1982.

. The logic of collective action: public goods and the theory of groups. Cambridge: Harvard University Press, 1965. Republicado em 1999 A lógica da ação coletiva. São Paulo: Editora da USP.

Ostrom, E. Collective action and the evolution of social norms. Journal of Economic Perspectives, v. 14, n. 3, Summer 2000.

Putnam, R. Making democracy work - civic traditions in modern Italy. Princeton: Princeton University Press, 1993.

Skidmore, T. Brasil: de Getúlio Vargas a Castelo Branco (1930-1964). São Paulo: Paz e Terra, 1992.

Vianna, S. B. Duas tentativas de estabilização. In: Abreu, M. P. (org.), A ordem do progresso. Rio e Janeiro: Campus, 1992.

. A politica econômica no segundo Governo Vargas (1951-1954). Rio de Janeiro: BNDES, 1987.

Williamson, O. The mechanisms of governance. New York: Oxford University Press, 1996. 
. The economic institutions of capitalism. New York: Free Press, 1985.

. Transaction-cost economics: the governance of contractual relations. Journal of Law and Economics, 22, October 1979. 